\title{
O IMPACTO DAS NOVAS TECNOLOGIAS NA DEMANDA DO LÍTIO'
}

Eduardo Vale ${ }^{2}$

\section{SINOPSE}

Este texto apresenta uma síntese do estudo sobre o lítio (Li) preparado pelo Ipea no âmbito da cooperação institucional (Termo de Execução Descentralizada - TED) com o Ministério de Minas e Energia (MME). $\mathrm{O}$ artigo oferece um diagnóstico horizontal, embora focado em tópicos selecionados, e uma análise do impacto das novas tecnologias na demanda do lítio. A partir da análise da situação atual, são discutidos cenários prospectivos de modo a referenciar as sugestóes de políticas e açôes setoriais de governo especificamente direcionadas à cadeia industrial do lítio.

Palavras-chave: economia mineral; aquecimento global; lítio; mineração; eletrificação; baterias; energias renováveis.

\section{INTRODUÇÃO}

Em meados dos anos 1990, a massificação no uso de dispositivos eletrônicos portáteis impulsionou a demanda por baterias recarregáveis a base de lítio. A partir de 2008, a importância do metal recebeu impulso com os compromissos internacionais relativos à reduçáo de emissóes de dióxido de carbono para mitigaçáo do aquecimento global. Em diversos países, estão sendo implementadas políticas públicas direcionadas à redução do consumo de combustíveis fósseis, com ênfase no aumento do uso de energias renováveis e no fomento à transição para veículos elétricos.

O relatório Minerals for climate action: the mineral intensity of the clean energy transition, do Banco Mundial, estimou o impacto na demanda de bens minerais selecionados provenientes da expansáo global esperada das energias eólica e solar, assim como a produção de baterias para veículos elétricos ou armazenamento em larga escala até 2050 (Hund et al., 2020). Esses vetores são considerados fundamentais para se alcançar a meta global de reduçáo mínima de $2^{\circ} \mathrm{C}$ no processo de aquecimento. Trata-se de processo intensivo no emprego de bens minerais e cuja intensidade será ampliada. O estudo incluiu o lítio no grupo dos minerais de grande impacto: "bens minerais utilizados por grupo restrito de tecnologias" (Hund et al., 2020, tradução nossa). As estimativas do Banco Mundial apontam para um crescimento de 965\% na demanda de lítio até 2050.

\section{BATERIAS DE ÍON-LÍTIO}

As baterias de íon-lítio são destinadas aos veículos elétricos e ao armazenamento em larga escala da energia gerada pelas fontes renováveis. Registre-se que essas baterias, relativamente às opçóes tecnológicas alternativas, caracterizam-se por oferecer menor peso e maior capacidade de armazenamento por períodos mais longos, além de suportarem alto número de ciclos de carga/descarga. A figura 1 ilustra a importância das baterias de íon-lítio na geração de energia renovável. 
Entre os três principais componentes da bateria de íon-lítio tem-se:

- o anodo, que tem a função de armazenar e liberar os íons de lítio para a corrente elétrica;

- o eletrólito, que encerra os sais de lítio e é o componente principal da bateria, pois possibilita o fluxo de íons entre o anodo e o catodo; e

- o catodo, que desempenha papel fundamental ao possibilitar a geraçáo de corrente elétrica mediante reação química.

Os materiais empregados dependem da tecnologia utilizada nos tipos de baterias:

- lithium cobalt oxide (LCO);

- lithium manganese oxide (LMO);

- lithium iron phosphate (LFP);

- lithium nickel manganese cobalt (NMC); e

- lithium nickel cobalt aluminum oxide (NCA).

\section{FIGURA 1}

Baterias de íon-lítio na geração de energia renovável

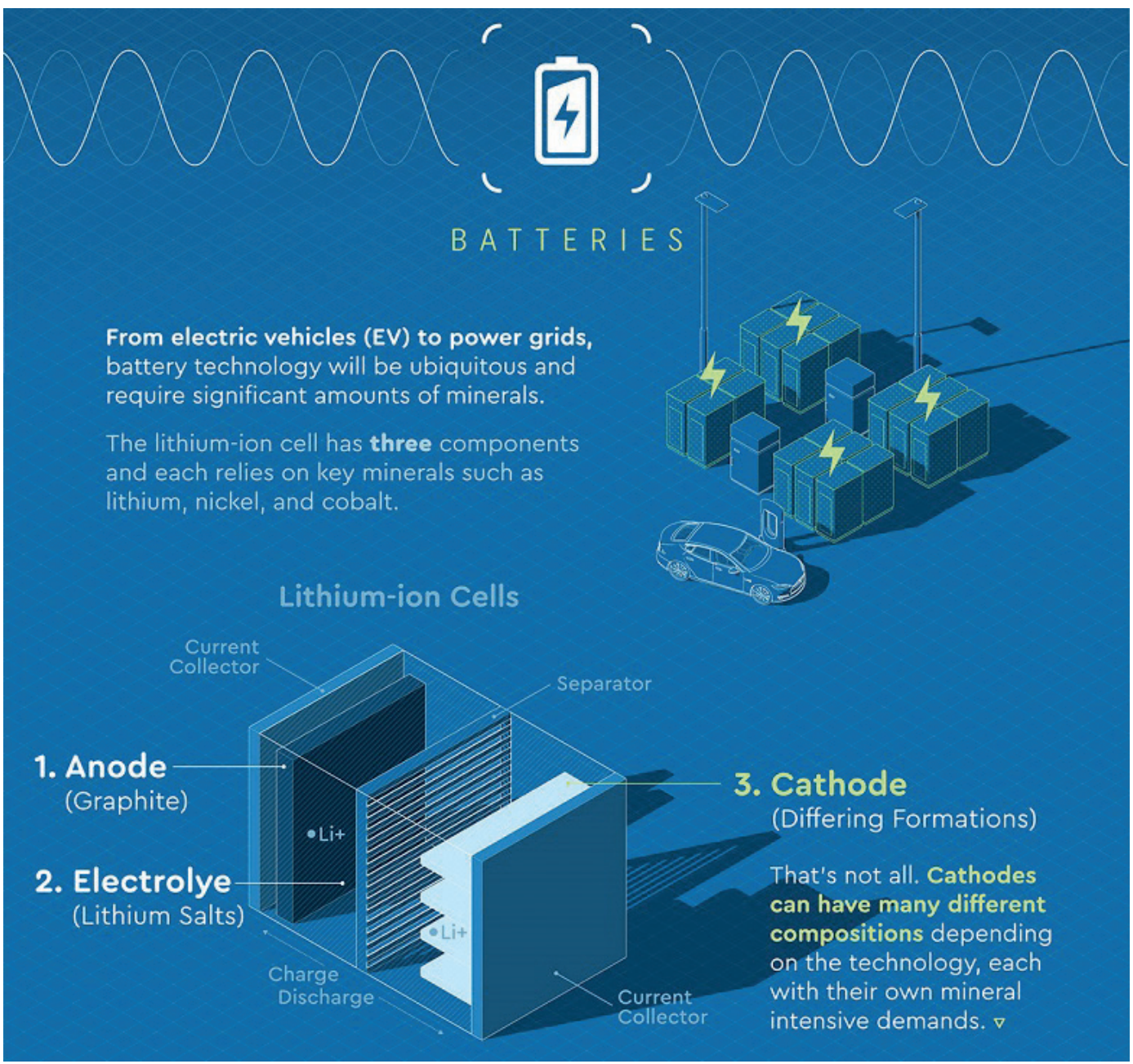

Fonte: Climate-smart mining: minerals for climate action. Disponivel em: <https://bit.ly/3uP1JLh>.

Obs.: Figura cujos leiaute e textos não puderam ser padronizados e revisados em virtude das condições técnicas dos originais (nota do Editorial). 


\section{CONSUMO DE LÍTIO}

O lítio e seus compostos químicos têm uma ampla gama de aplicaçôes na fabricação de baterias (primárias e recarregáveis), em vidro e cerâmica, em graxas lubrificantes, em ligas metálicas, em medicamentos e na indústria nuclear. No perfil setorial agregado do consumo global, tem-se: baterias, 65\%; cerâmica e vidro, 18\%; graxas, 5\%; polímero, 3\%; fundição, 3\%; tratamento do ar, $1 \%$; outros, $5 \%$.

A componente da demanda futura representada pela indústria de baterias é o vetor de maior relevância para o crescimento do consumo de lítio. A título ilustrativo, em 2013, no perfil do consumo mundial, a liderança era do setor de vidro e cerâmica (35\%), seguido por baterias (31\%), graxas lubrificantes (8\%), fundição (6\%); tratamento do ar $(5 \%)$, polímeros (5\%), alumínio (1\%) e outros (9\%). Em apenas seis anos, o segmento de baterias de íon-lítio mais do que dobrou sua participação relativa no consumo de lítio.

\section{DEMANDA DE LÍTIO}

Com o avanço das energias não renováveis e dos veículos elétricos, a trajetória de expansão da demanda estimada por baterias de íon-lítio provocará aumento expressivo na demanda desse mineral. As estimativas da Agência Internacional de Energia (AIE) indicam crescimento acentuado no número de carros elétricos e híbridos, cuja frota deverá evoluir de 7,2 milhóes de veículos elétricos (quatro rodas), em 2019, para cerca de 23 milhôes, em 2030. Nesse contexto, o avanço dos marcos regulatórios e a implementação de estímulos fiscais por países desenvolvidos assumem papel cada vez mais relevante no fomento à aceleração da taxa de penetração de veículos elétricos.

A partir dessas consideraçóes, o vetor de crescimento fundamental da demanda prospectiva de lítio, ao longo da próxima década, é o segmento de baterias do tipo íon-lítio, seja para mobilidade elétrica, seja para o armazenamento de energia em larga escala ou destinado ao segmento de produtos eletrônicos. Em 2030, a participação relativa do segmento de baterias deverá responder por aproximadamente $75 \%$ da demanda do metal. A empresa de consultoria Roskill e a empresa Albermale, maior produtora de lítio do mundo, trabalham com taxas médias de crescimento, para a década de 2020 , ao redor de $20 \%$ ao ano, com expectativa de uma demanda de 1 milhão de toneladas de carbonato de lítio equivalente (LCE) sendo alcançada por volta de 2026/2027 (Heathman, 2020; Albermale, 2020). Essa perspectiva sugere um mercado com pressão sobre os preços e incentivo ao desenvolvimento de novos projetos. No que diz respeito aos demais segmentos consumidores, como vidro, cerâmica, graxas lubrificantes, ligas metálicas, medicamentos e indústria nuclear, as expectativas são de crescimento moderado, ao redor de $5 \%$.

\section{O LÍTIO NO BRASIL}

Ao longo dos últimos dez anos, várias ações de governo foram implementadas para fomentar os minerais considerados estratégicos. Algumas dessas ações estão mencionadas no terceiro artigo desta edição do boletim Radar, referente à grafita. No que concerne especificamente ao lítio, merecem destaque o projeto Avaliação do Potencial do Lítio no Brasil, da Companhia de Pesquisa de Recursos Minerais (CPRM), e o Plano de Ciência, Tecnologia e Inovaçáo para Minerais Estratégicos 2018-2022. Entre as metas e açóes de ciência, tecnologia e inovação (CT\&I) propostas para superar o desafio tecnológico do lítio destaca-se a "Meta 1 - Desenvolver tecnologias e inovaçôes para produção e aplicação de lítio em produtos de alta tecnologia". Para a consecução da meta, são propostas algumas açóes na área de pesquisa, desenvolvimento e inovação (PD\&I). 
A Companhia Brasileira de Lítio (CBL) é a única produtora de lítio no país. Todavia, encontram-se em implantação dois projetos das empresas AMG Mineração e Sigma Mineração. A implantação desses projetos irá alavancar sobremaneira a inserçáo brasileira no mercado internacional. Por sua vez, ao contribuírem para descortinar o potencial mineral do país como produtor de lítio, oferecem lastro inicial para a implantação de uma política setorial direcionada à cadeia industrial do lítio.

Finalmente, a implantação dos primeiros projetos para a produção de baterias no Brasil sinaliza o reconhecimento do grande potencial do mercado interno brasileiro pelo lado da demanda por baterias. Diante dos compromissos internacionais do país, no que concerne à emissão de $\mathrm{CO}_{2}$, merece registro que, em se tratando de veículos elétricos, um dos segmentos que despertam grande interesse inicial é a substituição da grande frota de ônibus urbanos, assim como outras alternativas de mobilidade urbana em consideração, em diversos municípios.

\section{CONCLUSÕES E SUGESTÕES}

Em vários países desenvolvidos, as políticas direcionadas à redução do consumo de combustíveis fósseis e à eletrificaçáo da economia integram o eixo central do processo de retomada do crescimento. Trata-se de processo intensivo no uso de bens minerais.

O lítio não é considerado um metal raro. Não obstante, o predomínio do lítio como mineral crucial permeando a maioria das rotas tecnológicas alternativas para produção de baterias associado ao suprimento fortemente concentrado em termos de países e de empresas alçaram o metal, sob as óticas da segurança nacional e da garantia de suprimento, à categoria de mineral crítico. No plano nacional, a magnitude dos recursos e das reservas de lítio do país, assim como a dimensão do seu mercado doméstico potencial para baterias de íon-lítio, tanto para armazenamento quanto para veículos elétricos, o posiciona entre os minerais prioritários no que diz respeito à definição de uma política mineral específica.

Os fundamentos da demanda no longo prazo parecem sólidos e bem-colocados. Ao longo da década, as perspectivas para a demanda de lítio são excelentes. A despeito das condiçóes adversas de mercado após o impacto da Covid-19, que deverão perdurar até o final de 2021, existe um consenso quanto à robustez da demanda do lítio ao longo da década. O impacto nas decisóes de investimentos e a relativa intensidade do processo atual de ajustamento da oferta, especialmente no que concerne às suspensôes e às postergaçóes de projetos de expansão e de implantação, sugerem a possibilidade de que, a partir de 2022/2023, tenha início uma trajetória de elevação persistente do preço. Níveis de produção significativamente abaixo da demanda a partir de 2023 são prováveis. Este desequilíbrio potencial seria fruto da discrepância entre a alta elasticidade da demanda por baterias, em resposta à aceleração na demanda por veículos elétricos e por armazenamento de energia, diante da relativa inelasticidade do suprimento de concentrado de lítio no médio prazo, especialmente após a pandemia.

Em nível de sugestôes, são focalizadas três dimensões da economia do lítio: suprimento (exploração e produção mineral), tecnologia e demanda. Pelo lado da exploração mineral, visando acelerar o conhecimento dos recursos minerais, sugere-se a reavaliação dos resultados alcançados no projeto Avaliação do Potencial do Lítio no Brasil, da CPRM (Paes, 2018). O objetivo é selecionar subáreas específicas de alta prioridade, que justifiquem serem revisitadas para maior detalhamento e adensamento de informaçóes de geologia econômica (escala, amostragem, abertura de trincheiras etc.) em configuração e formato conceitual o mais próximo possível das necessidades do processo decisório do setor privado. Nesse contexto, inserem-se as questôes relativas ao aperfeiçoamento do modelo geológico dos depósitos de lítio, à identificação de novas áreas potenciais e à proposição de um modelo exploratório para os pegmatitos do tipo lítio-césio-tântalo (LCT). Pelo lado da produção, sugere-se atribuir prioridade e dinamizar a liberação dos processos de direitos minerários para lítio. 
Sob a ótica da tecnologia, sugere-se a realização de um inventário dos projetos de pesquisa tecnológica para o lítio: já executados, em execução ou previstos. Esse levantamento poderia ser realizado pelo Centro de Tecnologia Mineral (Cetem). Um dos gargalos fundamentais é a conversão química para a produção de hidróxido de lítio grau bateria. Um projeto em escala piloto seria um bom começo. Entre as opçóes, o estabelecimento de parcerias para cooperação internacional é uma alternativa que merece ser avaliada. Nesse caso, acredita-se que a Índia reúna características ideais que a credenciam como potencial parceiro a ser considerado. Finalmente, sob a ótica da demanda, tendo em vista a expansão acelerada das energias eólica e solar no país e o grande mercado potencial para veículos elétricos, sugere-se a realização de estudo prospectivo sobre a demanda de baterias.

\section{REFERÊNCIAS}

ALBERMALE. Investor presentation. In: JP MORGAN INDUSTRIALS CONFERENCE, 2020. Anais... Albermale, 2020. Disponível em: <https://bit.ly/3uP5hgz>. Acesso em: 25 jun. 2020.

HEATHMAN, O. Lithium: over 50\% of spodumene supply marginal in Q2 2020. Roskill, 27 Aug. 2020. Disponível em: <https://bit.ly/3dV14kA>. Acesso em: 25 jun. 2020.

HUND, K. et al. Minerals for climate action: the mineral intensity of the clean energy transition. Washington: World Bank, 2020. Disponível em: <https://bit.ly/3dhUuG3>.

PAES, V. J. de C. Avaliação do potencial do lítio no Brasil: ações, principais resultados, perspectivas atuais e futuras. Brasília: CPRM, 2018.

\section{BIBLIOGRAFIA COMPLEMENTAR}

ARROBAS, D. P. et al. The growing role of minerals and metals for a low carbon future. Washington: World Bank; EGPS, June 2017. (Working Paper, n. 117581). Disponível em: <https://bit.ly/2Q44TvV>.

VALE, E. Impacto das novas tecnologias na demanda mineral: o caso do lítio. Brasília: Ipea, ago. 2020. 86 p. 
